\title{
Effects of Secondary Tasks on Vehicle Speed and Distance during Driving and Brake Response Time during Unexpected Situation
}

\author{
Su-Jeong Lee ${ }^{1}$, Jae-Woong Yang ${ }^{1}$, Ji-Hye Kim ${ }^{1}$, Mi-Hyun Choi ${ }^{1}$, Han-Soo Kim ${ }^{1}$, \\ Jin-Seung Choi ${ }^{1}$, Byung-Chan Min $^{2}$, Gye-Rae Tack ${ }^{1}$, Soon-Cheol Chung ${ }^{1}$ \\ ${ }^{1}$ Department of Biomedical Engineering, Research Institute of Biomedical Engineering, \\ College of Biomedical \& Health Science, Konkuk University, Chungju, 380-701 \\ ${ }^{2}$ Department of Industrial \& Management Engineering, Hanbat National University, Daejeon, 305-719
}

\begin{abstract}
The purpose of this study was to investigate the effects of the secondary tasks such as sending text message(STM) and searching navigation(SN) on vehicle speed and distance during driving and brake response time during unexpected situation using a driving simulator. The participants included 19 college students; 9 males aged $25.2 \pm 1.0$ with $2.4 \pm 2.0$ years of driving experiences and 10 females aged $21.4 \pm 0.5$ with $1.3 \pm 0.5$ years of driving experiences. All subjects were instructed to keep a certain distance $(30 \mathrm{~m})$ from the car ahead and a constant $\operatorname{speed}(100 \mathrm{~km} / \mathrm{h})$. Average speed and average following distance were measured during 10 seconds before unexpected situation. Also, brake response time after unexpected situation was measured. Average speed was more decreased and average following distance was more increased during the driving with secondary tasks than driving only. Male maintained the assigned speed and distance better than female. The brake response time was faster during driving only than the driving with secondary tasks. And the brake response time of male was shorter than that of female.
\end{abstract}

Keywords: Secondary Task, Vehicle Speed and Distance, Brake Response Time, Unexpected Situation

\section{Introduction}

대부분의 성인들은 휴대 전화를 사용하고 있고, MP3 및 내비게이션 등 차량 내 전자기기의 보급이 크게 증가하고 있다. 이로 인해 운전 중 휴대 전화 및 차량 내 전자기기의 사용이 증가하고 있는 실정이다. 차량 내 전자기기의 사용 은 운전자에게 도로 및 교통 상황 등의 운전 정보를 알려 주기 때문에 긍정적으로 작용할 수도 있지만, 운전자에게 주의력 분산을 유발하여 안전 운전 측면에서는 부정적으로 작용할 수도 있다. 최근 미국 연방정부 도로교통 안전관리
청(National Highway Traffic Safety Administration, NHTSA)과 버지니아공대 교통연구팀(Virginia Tech Transportation Institute)의 연구에 따르면 교통사고의 25 80\%는 운전자의 주의력 분산에 의해 발생한다고 보고 되었다(Dingus et al., 2006).

운전 중 주의력 분산을 유발할 수 있는 동시 과제 수행과 관련한 많은 연구들이 수행되어 왔다. Jamson과 Merat (2005)는 운전 중 시각 과제와 청각 과제 수행이 운전 수행 능력에 미치는 영향에 대해 살펴보았다. Anttila와 Luoma (2005)는 주의력 분산 과제의 난이도에 따라 운전 수행 능 력을 비교하였다. 또한 운전 중 휴대 전화 사용과 TV 시청

Corresponding Author: Soon-Cheol Chung. Department of Biomedical Engineering, Research Institute of Biomedical Engineering, College of Biomedical \& Health Science, Konkuk University, Chungju, 380-701.

Mobile: 010-7449-3352, E-mail: scchung@kku.ac.kr

Copyright@2011 by Ergonomics Society of Korea(pISSN:1229-1684 eISSN:2093-8462). All right reserved. 
이 운전 수행 능력에 미치는 영향에 관한 많은 연구도 수행 되었다(Shin, 2000, Haigney et al., 2000; Strayer et al., 2002; Hancock et al., 2003; Strayer and Drews, 2003; Shin et al., 2006; Shin and Ryu, 2008). 이러한 선행 연구 들은 운전 중 동시 과제 수행이 운전 수행 능력을 감소시킨 다는 일관된 결과를 보고하였다. 또한 동시 과제 수행이 운 전 수행 능력에 미치는 영향은 남녀에 따라 차이가 있다는 보고도 있었다(Hancock et al., 2003).

선행 연구들은 대부분 운전 중 휴대 전화를 이용한 통화, $\mathrm{TV}$ 시청 등과 같은 주의력 분산 과제가 운전 수행 능력에 어떠한 영향을 미치는지에 대해 규명하고자 하였다. 그러나 최근에는 정보기기의 발달로 인해 운전 중 휴대 전화 통화 또는 TV 시청뿐만 아니라 휴대 전화를 이용한 문자 메시지 전송과 내비게이션의 사용 또한 증가하고 있는 실정이다. 그 러나 이에 대한 연구는 전무하다.

본 연구에서는 운전 중에도 동시에 작업할 수 있는 문자 메시지 전송과 내비게이션 검색과 같은 동시 과제의 수행이 운전 수행 능력에 미치는 영향에 대해 구체적으로 분석하고 자 한다. 특히, 돌발 상황 발생 시 이러한 주의력 분산 과제 가 운전 수행 능력에 어떠한 영향을 미치는지 규명하고자 한다. 또한 이들 두 동시 과제 사이에, 그리고 남녀 사이에 운전 수행 능력에 미치는 주의력 분산의 영향이 차이가 있는 지를 살펴보고자 한다.

\section{Methods}

\subsection{Subjects}

운전 경력이 $2.4 \pm 2.0$ 년인 건강한 성인 남자 9 명(평균 $25.2 \pm 1.0$ 세) 과 운전 경력이 $1.3 \pm 0.5$ 년인 성인 여자 10 명 (평균 $21.4 \pm 0.5$ 세)을 피험자로 선정하였다. 실험 전 실험 내용을 충분히 숙지할 수 있도록 피험자에게 설명하였다.

\subsection{Vehicle simulator}

본 실험에 이용된 화상 자동차 시뮬레이터 $(G D S-300 S$ Gridspace Co.)는 실험실에 설치되어 있는 모의용 기기로 3 대의 32 인치 LCD 모니터를 통해 운전 시 필요한 정면과 좌/우 환경 정보들을 제공하도록 구성되었다. 차량 모델은 $\mathrm{H}$ 사의 $\mathrm{C}$ 모델로서 운전 장치 (핸들, 가속페달, 브레이크 페달, 파킹브레이크, 방향지시등 레버, 비상등, 와이퍼 레버, 전조 등 레버, 기어 레버, 안전벨트 등)와 표시 장치(방향지시등, 속도계, $\mathrm{RPM}$ 미터, 온도게이지, 연료량 게이지, 각종 경고 등)는 실제 차량과 동일하였다. 핸들 장치는 motor driven power steering (MDPS) 의 모터제어 방식을 사용하였다.

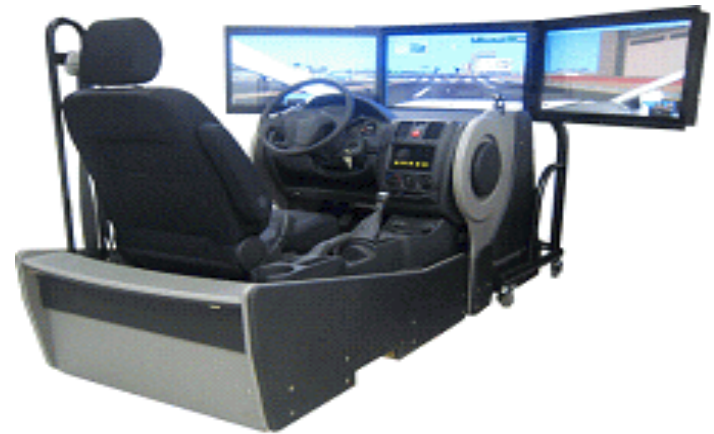

Figure 1. Vehicle simulator

\subsection{Experiment paradigm}

실험은 3 분간의 휴식(Rest) 구간, 1 분간의 운전(Driving) 구간, 그리고 1 분간의 운전(Driving) 또는 동시 과제(Driving +Secondary task) 구간으로 구성되었다(그림 1). 이때 처 음 1 분간의 운전 구간은 simulator 운전에 적응하는 구간 이다. 2 분간의 운전 구간 및 동시 과제 구간에서는 피험자 에게 편도 3 차선 도로를 $100 \mathrm{~km} / \mathrm{h}$ 로 주행하는 선행 차량 과 $30 \mathrm{~m}$ 의 일정한 차간 거리를 유지하며, $100 \mathrm{~km} / \mathrm{h}$ 의 속 도로 주행하게 하였다. 이때 선행 차량과의 거리 정보는 시뮬레이터 화면 하단에 표시하였다.

피험자들은 그림 1 의 실험 절차를 2 번 수행하며, 랜덤하 게 2가지의 동시 과제를 모두 수행하였다.

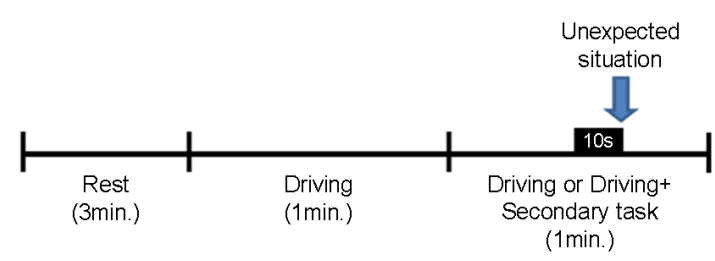

Figure 2. Experiment paradigm

동시 과제는 Sending Text Message(STM) 또는 Searching Navigation(SN)으로 구성되었다. STM 과제는 본인이 현재 사용하고 있는 휴대 전화를 이용하여 문자 메시 지를 전송하는 과제로서, 실제 차량 운전 시 전송 가능한 간 결한 문장으로 구성하였다(ex. 지금은 운전 중이니 잠시 후 전화드리겠습니다). $\mathrm{SN}$ 과제는 본 연구팀에서 제공한 내비 게이션을 이용하여, 건물의 명칭을 검색하는 과제였다(ex. 건국대학교 서울캠퍼스). 본 연구팀에서 제공한 내비게이션 은 현재 피험자가 사용하고 있지 않은 모델일 수 있기 때문 
에 실험에 앞서 충분한 연습을 통해 기기에 익숙해지도록 하였다.

동시 과제 수행 시 휴대 전화는 운전자에게 가장 편한 위 치에 두고 실험을 수행하도록 하였고, 내비게이션은 부착 형으로 피험자의 오른쪽 상단에 부착하여 고정된 위치에서 실험을 수행하도록 하였다. 피험자에게 지정된 차간 거리 (30m) 및 속도 $(100 \mathrm{~km} / \mathrm{h})$ 에 유의하여 운전을 수행하도록 지시하였다.

동시 과제 구간에서는 동시 과제 수행과 함께 돌발 상황 이 일어나도록 시나리오를 구성하였다(그림 1). 피험자에 게 동시 과제구간 내내 동시 과제를 수행하도록 지시하였으 며, 실험자가 키보드 조작으로 앞선 선행 차량을 임의로 멈 출 수 있도록 하여 순간적인 돌발 상황을 유도하였다. 이때 선행 차량이 급정거하는 순간을 돌발 상황(Unexpected situation)이라고 정의하였다.

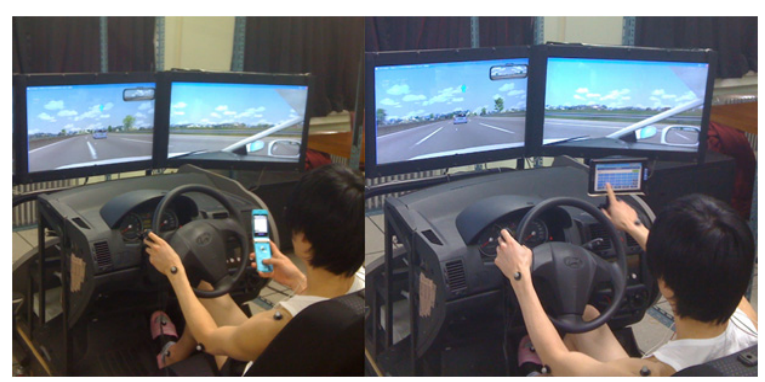

Figure 3. Secondary task performance

\subsection{Data measurement and analysis}

돌발 상황이 일어난 순간부터 피험자가 브레이크를 밟을 때까지의 시간을 브레이크 반응시간으로 정의하였다. 또한 돌발 상황이 일어나기 직전 10 초 동안의 평균 속도 및 평 균 차간 거리를 계산하였다(그림 1). 성별과 상황(Driving, Driving+STM, Driving+SN) 에 따라 브레이크 반응시간, 평균 속도 및 평균 차간 거리가 통계적으로 어떠한 차이가 있는지를 알아보기 위해 이원반복측정변량분석(two-way repeated ANOVA, SPSS ver. 18.0)을 수행하였다.

\section{Results}

돌발 상황 전 10 초 동안의 평균 속도는 상황 $(p<.01)$ 과 성별 $(p<.05)$ 에 따라 유의한 차이가 나타났다. 즉, 운전만 수행했을 때 보다 운전+동시 과제 수행 시 지정된 속도
$(100 \mathrm{~km} / \mathrm{h})$ 보다 평균 속도는 감소하는 경향을 보였다. 상황 에 대한 Bonferroni 사후검증 결과, Driving과 Driving+ $\mathrm{SN}$ 간 평균 속도에 유의한 차이가 나타났다 $(p<.05)$. 또한 여자에 비해 남자가 지정된 속도를 잘 유지한 것으로 나타 났다.

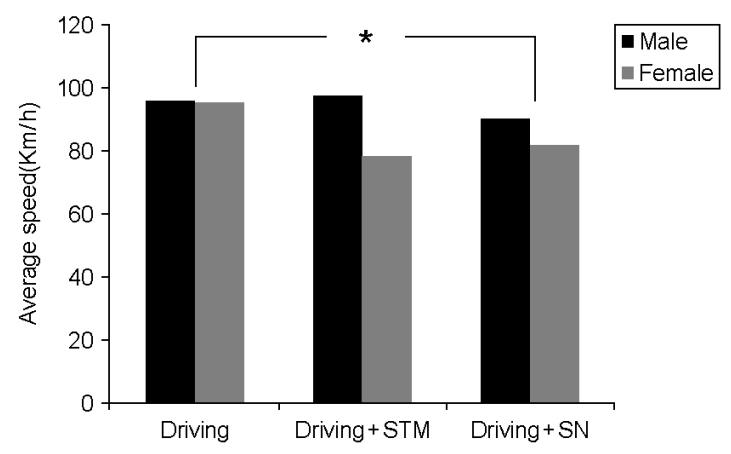

(a) Average speed

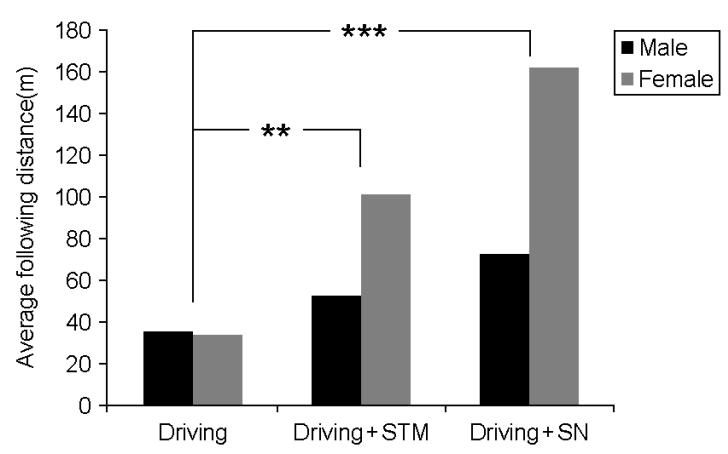

(b) Average following distance

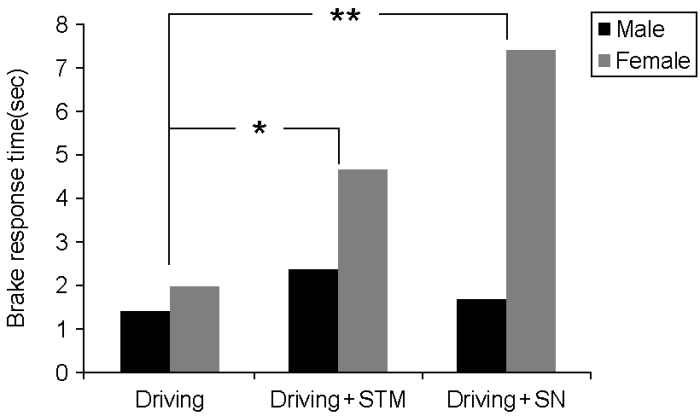

(c) Brake response time

Figure 4. Results of Average speed, Average following distance, Brake response time from two-way repeated ANOVA, using condition and gender

돌발 상황 전 10 초 동안의 평균 차간 거리도 상황 $(p$ <.001) 과 성별 $(p<.01)$ 에 따라 유의한 차이가 나타났다. 즉, 
운전만 수행했을 때 보다 운전+동시 과제 수행 시 지정된 차간 거리 $(30 \mathrm{~m})$ 보다 평균 차간 거리는 증가하는 경향을 나 타내었다. 상황에 대한 Bonferroin 사후검증 결과, Driving 과 Driving $+\mathrm{STM}$ 간, Driving 과 Driving $+\mathrm{SN}$ 간 평균 차 간 거리에 유의한 차이가 나타났다 $(p<.01, p<.001)$. 또한 여자에 비해 남자가 평균 차간 거리를 더 잘 유지하였다 $(p<.01)$.

브레이크 반응시간의 이원반복측정변량분석 결과, 상황 $(p<.001)$ 과 성별 $(p<.01)$ 에 따라 유의한 차이가 나타났다. 즉, 돌발 상황 발생 시 운전만 수행했을 때 보다 운전 +동시 과제 수행 시 브레이크 반응시간이 증가하였다. 상황에 대한 Bonferroni 사후검증 결과, Driving과 Driving+STM 간, 그리고 Driving과 Driving + SN 간 브레이크 반응시간에 유의한 차이가 나타났다 $(p<.05, p<.01)$. 또한 여자에 비해 남자의 브레이크 반응시간이 더 짧았다.

\section{Discussion and conclusion}

본 연구에서는 운전 중 문자 메시지 전송, 내비게이션 명 칭 검색과 같은 동시 과제 수행이 운전 수행 능력에 미치는 영향을 살펴보고자 하였다. 즉, 동시 과제 수행이 선행 차량 과의 거리 유지 그리고 속도 유지와 같은 운전 수행 능력에 어떠한 영향을 미치는지 그리고 예측하지 못한 돌발 상황에 대한 운전 대처 능력에 어떠한 영향을 미치는지 규명하고자 하였다.

Jamson과 Merat(2005)는 운전 중 시각 과제와 청각 과 제 수행이 운전 수행 능력에 미치는 영향을 살펴보았다. 그 결과 두 과제 모두 돌발 상황에 대한 대처 반응시간을 길게 하였다고 보고하였다. 즉, 운전 중 동시 과제 수행은 운전 수 행 능력에 부정적인 영향을 유발할 수 있다고 결론지었다.

운전 중 휴대 전화 사용이 운전 수행 능력에 미치는 영향 에 관한 많은 연구가 수행되어 왔다(Shin, 2000; Haigney et al., 2000; Strayer et al., 2002; Hancock et al., 2003; Strayer and Drews, 2003). 운전 중 휴대 전화 통화로 인 해 주행 속도가 감소하였으며 (Shin, 2000; Haigney et al., 2000), 돌발에 대한 반응시간이 길게 나타났다고 보고하였 다(Shin, 2000; Strayer et al., 2002). 운전 중 휴대 전화 를 이용한 통화로 인해 전방 차량과의 거리가 증가하였다는 연구도 보고되었다(Strayer et al., 2002; Strayer and Drews, 2003). 또한 Hancock 등(2003)은 운전 중 휴대 전화의 다이얼을 누르는 과제 수행 시 돌발 상황에 대한 남 녀 반응의 차이를 살펴 본 결과, 남자에 비해 여자의 반응시 간이 더 느리게 나타났다고 보고하였다.
차량 시뮬레이터를 이용하여 운전 중 $\mathrm{TV}$ 를 시청하는 집 단과 $\mathrm{TV}$ 를 시청하지 않는 집단을 대상으로 $\mathrm{TV}$ 시청이 운 전 행동에 미치는 영향을 규명하고자 하는 연구가 수행된 바 있다(Shin et al., 2006; Shin and Ryu, 2008). 연구 결 과, 운전 중 $\mathrm{TV}$ 를 시청하는 집단이 시청하지 않는 집단에 비해서 돌발 상황에 대한 반응시간이 더 길게 나타났으며, 주행 속도 편차 및 전방 차량과의 거리 편차도 더 크게 나타 났다고 보고하였다. 즉, TV 시청으로 인해 주행 속도 및 차 량 간의 거리를 일정하게 유지하는 능력이 저하된 것으로 판 단하였다.

본 연구 결과 선행 연구들과 유사하게 운전 중 문자 메시 지 전송 및 내비게이션 명칭 검색의 동시 과제 수행으로 평균 속도는 감소하였고, 평균 차간 거리는 증가하였다. 또 한 돌발 상황 발생 시 동시 과제 수행이 브레이크 반응시간 을 증가시켰다. 즉, 운전 중 휴대 전화 통화 또는 $\mathrm{TV}$ 시청 이 운전 수행 능력을 감소시켰던 선행 연구들과 유사하게 (Shin, 2000, Haigney et al., 2000; Strayer et al., 2002; Hancock et al., 2003; Strayer and Drews, 2003; Shin et al., 2006; Shin and Ryu, 2008), 문자 메시지 전송 또는 내 비게이션의 명칭 검색의 동시 과제 수행도 분명한 운전 수 행 능력 저하를 유발하였다.

본 연구 결과 문자 메시지 전송에 비해 내비게이션 명칭 검색의 동시 과제 수행 시 운전 수행 능력의 저하(평균 속도 의 감소, 평균 차간 거리의 증가, 브레이크 반응시간의 증 가)가 더 크게 나타나는 경향을 보였다. 이것은 운전자가 편 한 위치에서 제어할 수 있는, 즉 운전 수행에 영향을 적게 끼치는 문자 메시지 전송에 비해 고정된 위치에 있어서 운전 자가 편한 상황에서 조작할 수 없는 내비게이션 명칭 검색이 안전 운전에 더 부정적인 영향을 미칠 가능성이 있다는 것을 의미한다. 그러나 본인이 현재 사용하고 있는 휴대폰과 비교 하여 내비게이션의 경우 본인의 것이 아니기 때문에 사용 경 험이 부족하여 조작에 대한 어려움이 있을 수 있었고, 이것 이 본 연구 결과에 영향을 미칠 수 있었을 것으로 판단된다.

본 연구 결과 동시 과제 수행 시 지정된 속도 및 차간 거 리를 여자에 비해 남자가 잘 유지하였고, 선행 연구와 유사 하게 돌발 상황에서 여자보다 남자의 브레이크 반응시간이 더 짧게 나타났다(Hancock et al., 2003). 이것은 운전 중 동시 과제 수행으로 남자에 비해 여자가 더 위험할 수 있다 는 것을 의미한다. 그러나 본 실험에서는 남녀의 운전 경력 이 차이가 있었기 때문에 이러한 결과가 나타났을 수도 있 다. 성별에 따른 차이는 향후 동일한 조건의 피험자 선정을 통한 추가 실험을 통해 규명되어져야 할 것이다.

결론적으로, 본 연구 결과 문자 메시지 전송과 내비게이션 명칭 검색은 운전 수행 능력을 저하시켰고, 내비게이션 명칭 검색이 운전 수행 능력에 더 큰 영향을 미치는 경향이 나타 
났다. 또한 동시 과제 수행이 운전 수행 능력에 미치는 영향 은 성별에 따라 차이가 있을 가능성이 있었다. 본 연구 결과 는 안전 운전 수행을 위한 가이드라인 제시에 활용될 수 있 을 것이다.

\section{Acknowledgements}

This work was supported by Mid-career Researcher Program through NRF grant funded by the MEST(No. 2009-0084784).

\section{References}

Anttila, V. and Luona, J., Surrogate in vehicle information system and driver behaviour in an urban environment-: A field study on the effects of visual and cognitive load, Transportation Research Board: Part F, 8, 121-133, 2005.

Dingus, T. A., Klauer, S. G., Neale, V. L., Petersen, A., Lee, S. E., Sudweeks, J., Perez, M. A., Hankey, J., Ramsey, D., Gupta, S., Bucher, C., Doerazph, Z. R., Jermeland, J. and Knipling, R. R., The 100-car Naturalistic Driving Study, Phase II-Results of the 100-car field experiment, National Highway Traffic Safety Administration, Washington DC, USA, 2006.

Hancock, P. A., Lesch, M. and Simmons, L., The distraction effects of phone use during a crucial driving maneuver, Accident Analysis and Prevention, 35(4), 501-514, 2003.

Haigney, D. E., Taylor, R. G. and Westerman, S. J., Concurrent mobile (cellular) phone use and driving performance: Task demand characteristics and compensentory processes, Transportation Research Part F, 3, 113-121, 2000.

Jamson, A. H. and Merat, N., Surrogate in-vehicle information system and driver behavior: Effects of visual and cognitive load in simulated rural driving, Transportation Research Board Part F, 8, 79-86, 2005.

Shin, Y. K., Effects of on mobile phone on driving performance during driving, KOROAD, 2000.

Shin, Y. K., Lim, P. N., Kang, S. C. and Ryu, J. B., The effects of in vehicle watching DMB on driver behavior, Journal of Korea Transportation Research Society, 24(3), 103-112, 2006.

Shin, Y. K. and Ryu, J. B., The effect of operating telematics device in vehicle on driver behaviors, Journal of Korea Transportation Research Society, 26(6), 39-47, 2008.

Strayer, D. L., Drews, F. A., Alvert, R. W. and Johnston, W. A., Why do cell phone conversations interfere with driving?, Proceedings of the 81 $1^{\text {st }}$ Annual Transportation Research Board Meeting, 2002.

Strayer, D. L. and Drews, F. A., Effects of cell phone conversations on younger and older drivers, Human Factors and Ergonomics Society
Annual Meeting Proceedings, 1860-1864, 2003.

\section{Author listings}

Su Jeong Lee: sjlee618@gmail.com

Highest degree: M.S., Department of Biomedical Engineering, Konkuk University

Position title: M.S., Department of Biomedical Engineering, Konkuk University

Areas of interest: Brain Imaging, Physiological Signal

Jae-Woong Yang: jwyang1@kku.ac.kr

Highest degree: B.E., Department of Biomedical Engineering, Konkuk University

Position title: Master course, Department of Biomedical Engineering, Konkuk University

Areas of interest: Brain Imaging, Physiological Signal

Ji-Hye Kim: kimjh1106@gmail.com

Highest degree: B.E., Department of Biomedical Engineering, Konkuk University

Position title: Master course, Department of Biomedical Engineering, Konkuk University

Areas of interest: Brain Imaging, Physiological Signal

\section{Mi-Hyun Choi: mhchoi0311@gmail.com}

Highest degree: M.S., Department of Biomedical Engineering, Konkuk University

Position title: PhD candidate, Department of Biomedical Engineering, Konkuk University

Areas of interest: Brain Imaging, Physiological Signal

Han Soo Kim: hanskim03@gmail.com

Highest degree: B.E., Department of Biomedical Engineering, Konkuk University

Position title: Master course, Department of Biomedical Engineering, Konkuk University

Areas of interest: Biomechanics, Motion Analysis

Jin Seung Choi: jschoi98@gmail.com

Highest degree: M.S., Department of Biomedical Engineering, Konkuk University

Position title: $\mathrm{PhD}$ candidate, Department of Biomedical Engineering, Konkuk University

Areas of interest: Biomechanics, Gait, Nonlinear analysis 
Byung Chan Min: bcmin@hanbat.ac.kr

Highest degree: Ph.D., Department of System Engineering, The University Electro-Communications in Tokyo

Position title: Professor, Department of industrial and management

Engineering, Hanbat National University

Areas of interest: User Interface, Biosignal Processing

Gye Rae Tack: grtack@kku.ac.kr

Highest degree: Ph.D., Department of Biomedical Engineering,

University of Iowa, USA

Position title: Professor, Department of Biomedical Engineering, Konkuk

University

Areas of interest: Biomechanics

\section{Soon Cheol Chung: scchung@kku.ac.kr}

Highest degree: Ph.D., Degree in Electrical Engineering, Korea Advanced Institute of Science and Technology

Position title: Professor, Department of Biomedical Engineering, KonKuk University

Areas of interest: Brain Imaging, Physiological Signal

Date Received : 2010-09-17

Date Revised : 2011-05-24

Date Accepted : 2011-05-24 